\section{WIND STRUCTURE IN THE TRADES}

$I^{\mathrm{T}}$

$T$ is now forty-two years since Sir Geoffrey Taylor inaugurated modern scientific study of the dynamics of wind in the lower layers of the atmosphere with his theoretical and experimental work on turbulent viscosity published in the Philosophical Transactions of the Royal Society in 1915. That work was a direct consequence of the sinking of the Titanic and 'Taylor's appointment to investigate, in the Scotia, the meteorology of the ocean area in which the Titanic sank.

The latest research on the subject is that by H. Charnock, J. R. D. Francis and P. A. Sheppard in the same series (Phil. Trans., A, No. 963, 249; Oct. 1956). These workers made 466 double-theodolite pilot balloon ascents from the island of Anegada in the West Indies in the spring of 1953. This island is in the easterly trade-wind belt. The trade winds in this area are very suitable for detailed study of wind structure because of their comparative constancy and, above all, because they decrease with height above the relatively small height of $350 \mathrm{~m}$. The decrease above this height is due to the fact that the air temperature at a fixed height increases from north to south, so that the north to south fall of pressure, giving easterly winds, decreases with height. Up to $1,000 \mathrm{ft}$. the wind increases with height because of increasing distance from the sea surface. This kind of variation of wind with height permits calculation of the drag exerted by the ocean on the wind. The value of the drag for these winds, of speed about $6 \mathrm{~m} . / \mathrm{s}$. , is 0.41 dynes $/ \mathrm{cm}^{2}$, which corresponds to a drag coefficient of $1.24 \times 10^{-3}$. There were also evaluated the variation with height of the downwind and crosswind eddy stresses, the coefficient of turbulent viscosity and the eddyvelocity products.

The downwind coefficient of turbulent viscosity came out at about $1 \times 10^{5} \mathrm{~cm} .{ }^{2} / \mathrm{sec}$. and the cross. wind one about three times as great.

The eddy velocity products, $\left(u^{\prime}\right)^{2}$, etc., showed that the turbulence was not isotropic at any height in the layer, 1,350 m. deep, through which observations were made. The downwind eddy velocity variances were of the order of $50,000(\mathrm{~cm} . / \mathrm{sec} .)^{2}$, the crosswind ones about 120,000 and the vertical ones 1,200 at most. This is rather a surprising result, showing that the damping effect of the sea surface on vertical eddy movements extends to a greater height than had earlier been realized.

\section{SOME RECENT ASTRONOMY AT TOKYO}

T HE Annals of the Tokyo Astronomical Observatory (University of Tokyo. Second Series, 4, No. 3 ; 1956) contain two papers, the first of which is "Tables for the Approximate Special Perturbations by Means of the Variation of Parameters", by Tadao Takenouchi. With mean anomaly for every 10 degrees from $0^{\circ}$ to $180^{\circ}$, nine coefficients have been computed to three-decimal accuracy, except in the case of the eccentricity, where two-decimal accuracy is sufficient. The coefficients are as follows: $\alpha=$ $\cos E-e, \beta=\sin E, \gamma=-\sin E /(1-e \cos E), \delta=\cos E /$ $(1-e \cos E), \quad \lambda=-2 e \sin E, \quad \mu=(1-e \cos E)^{2}, \quad \nu=$ $-1 / \mu^{1 / 2}$.
The tables can also be adapted for the computation of ephemerides. A numerical example of their application is given.

The second paper, by Masatoshi Kitamura and Tsuyoshi Nakamura, with the title "A Photoelectric Study of the Atmospheric Extinction at Tokyo Astronomical Observatory", deals with the weaken. ing of starlight passing through the Earth's atmosphere; this weakening is caused by absorption and scattering due to particles in the atmosphere, and the amount of extinction and its dependence on wavelength are important in the reduction of spectral photometry. Pure extinction is due to the molecules of pure air, while haze effect is caused by water vapour, dust and smoke, the amounts of these continually varying; this haze effect is conventionally known as 'dust' extinction. As the Observatory is at Mitaka, a suburb of Tokyo, local conditions require that observations should be carried out towards the west, and these were made with the photoelectric apparatus attached to the 26-in. refractor of the Observatory, from the zenith towards the western horizon. The selected stars were $\beta$ And. and $\beta$ Tri., spectral type M0 and A5, respectively, and the observations were carried out on December $5-6$, 1955, and January 9-10, 1956. Observations were made in 1951 by T. Dambara with the same apparatus on $\alpha$ Gem. $A(\mathrm{~A} 0)$, and these were placed at the disposal of the authors. All three stars pass close to the zenith at Tokyo.

The reduction of observations was based on the well-known formula $\Delta M=k \sec Z$, where $\Delta M$ is the loss of light in magnitude, and $k$ is the extinction coefficient. This varies with the wave-length of the light, and formulæ for corrections of this and other disturbing factors are provided for use in the compilation of the extinctions given in Tables $1 a, 1 b, 2 a$, $2 b, 3$ for the stars selected. The results of extinction observations, extinction coefficients and absolute humidity are shown graphically and there is a short discussion on the dust absorption $k_{D}$, the variable part of which is mostly due to the amount of water. vapour, for the lower atmosphere may be considered to absorb the starlight at discrete wave-lengths. Taking into consideration all the meteorological conditions at Tokyo, it is considered that no useful results would be obtained by discussing the atmospheric extinction there from data for zenith distances greater than $60^{\circ}$.

\section{IMPACT OF INDUSTRIALIZATION ON RURAL LIFE IN THE BELGIAN CONGO}

A $\mathrm{N}$ account of the impact of industrialization on A rural life in the Belgian Congo has been given by the Rev. J. E. Young, of the Baptist Missionary Society (Rural Life J., No. 10; November 1956). The developments have taken place under the guidance of the Belgian Colonial Government, and this administration has achieved a considerable degree of success, perhaps a higher degree than most of its neighbours in Africa.

Stanley's journey nearly eighty years ago revealed a vast country of enormous potential wealth. To exploit this wealth, 280 miles of railway were built from the coast, by-passing the rapids of the lower Congo. The vision and judgment of King Leopold 
and a small group of pioneer enthusiasts carried this through by 1900 , so setting the scene for the establishment of law and order and the development of the country.

Trade in the early days consisted of bartering for palm oil, palm nuts and rubber, all gathered in the raw state by Africans. With the railways came the establishment of plantations by companies, including those that now form the Lever Group. Copper was discovered in the south-east, bordering Northern Rhodesia, then gold in the north-east, followed by diamonds and tin, and finally uranium. Mining developed steadily until 1929 and, after a slump, began to recover when the Second World War broke out.

Before the War, the established pattern of economy was mining in the south-east and north-east, and elsewhere, where soil and climate permitted, agriculture. Now a vast change is taking place ; Belgium, mindful of its own strategic position, is sending more of its citizens to the Congo, and starting every type of industry. Consequently, the population of Leopoldville, the capital, has grown in twenty years from 50,000 to 350,000 and will reach 500,000 by 1960 . In other centres, too, light industry is being developed.

Light manufacturing industries are operated in smaller units than mines and cannot spend large sums on welfare schemes. They are, howover, situated in large cities which cast the spell of high wages over the African, but living conditions are nowhere near as good as in mining 'camps'. Recently, the Government has, by direct action, and by pressure on employers, launched building work in all the big citios. Africans, assisted by a Government-sponsored 'building society', can and do buy their own houses. Social services have been greatly expanded, but the population has grown too fast for them. There is an acute shortage of teachers.

New factories and houses go up constantly, creating a demand for man-power that drains the countryside of its young men. The territory of Kasangulu has been so depopulated that the Government colonized it with other Africans and granted them credit to start market gardening. The magnetic draw of the capital is felt two hundred miles away, some villages having only old men, women and children left.

The impact of industrialization has done great harm to rural communities; but the Government is alive to the situation, and is eager to maintain the rural population. Employers also realize that productivity depends upon a healthy, contented and stable labour force. Plantation companies followed the lead of the mining companies in improving conditions, which resulted in a stabilization of the workers' families and a change in the shape of the rural community. Around existing plantations were created zones of influence where villagers made palm plantations on their own land. The scheme operated under a tripartite contract: villagers provided land and labour; the company provided seed, transport and a market ; the Government supervised, advised, maintained roads and arbitrated between villagers and the company.

The Government is faced with the problem that the economic development of the Belgian Congo demands that urban populations grow, and grow rapidly; but they must also be fed by a stable and contented rural population. The Congo imports food from neighbouring Colonies and from overseas. To solve this problem the Government has created peasant settlements (paysannats indigenes). These smallholding communities are organized to make the best use of land and to increase both productivity and soil fertility, and each settlement is large enough to provide worth-while social services.

The first of these settlements was at Torumbu, seventy miles from Stanleyville. Since 1942 long strips of land running east and west have been cleared and planted each year; these cultivated strips are separated by forest strips of equal widths of about a hunared yards. The chief allocated each peasant a portion of each strip as it was brought into culti. vation. This he farmed for three years and the produce belonged to him absolutely; after three years the land went back to the chief and was rested for fifteen years. Peasants each had an additional plot of one acre near their houses and other plots in a perennial plantation of oil palm and coffee. The homestead plots were in groups of about thirty and formed hamlets, a number of which were sited around the community centre. The crops grown and sold were maize, bananas, rice, cassava, peanuts and soya. A co-operative was formed to organize marketing, and later acquired farm machinery. The success of the venture is now assured; in 1953, two thousand cultivators were living on the settlement and the drift to the towns had ceased.

The Belgian Government is pressing forward with the extension of this valuable system. By 1958 it is hoped that half a million peasants will be suited; with their families they will form one-sixth of the country's population.

\title{
EFFECT OF HEXCESTROL ON CARCASS COMPOSITION AND EFFICIENCY OF FOOD UTILIZATION IN FATTENING LAMBS
}

\author{
By T. R. PRESTON and ISOLINE GEE \\ Rowett Research Institute, Bucksburn, Aberdeenshire
}

QYNTHETIC cestrogens have been shown to
induce greater and more economical live-weight
gains in lambs $1-7$. To some extent these advantages
have been offset by consistent reports of a reduction
in carcass quality ${ }^{2-8}$. Where detailed carcass studies
have been made ${ }^{4}$, it was found that the subcutaneous
fat was thinner and contained more moisture, but
that there was little change in muscle measurements or intermuscular fat. It was suggested ${ }^{9}$ that the increase in live-weight and subsequent carcass weight of treated lambs might be entirely due to an increase in moisture content of the tissues and a greater percentage of offal. These conclusions have been based on limited analyses of small sample joints, such as the 11-12-13 rib cut. Since ostrogens alter the conformation of the animal ${ }^{10}$ and may affect parts 